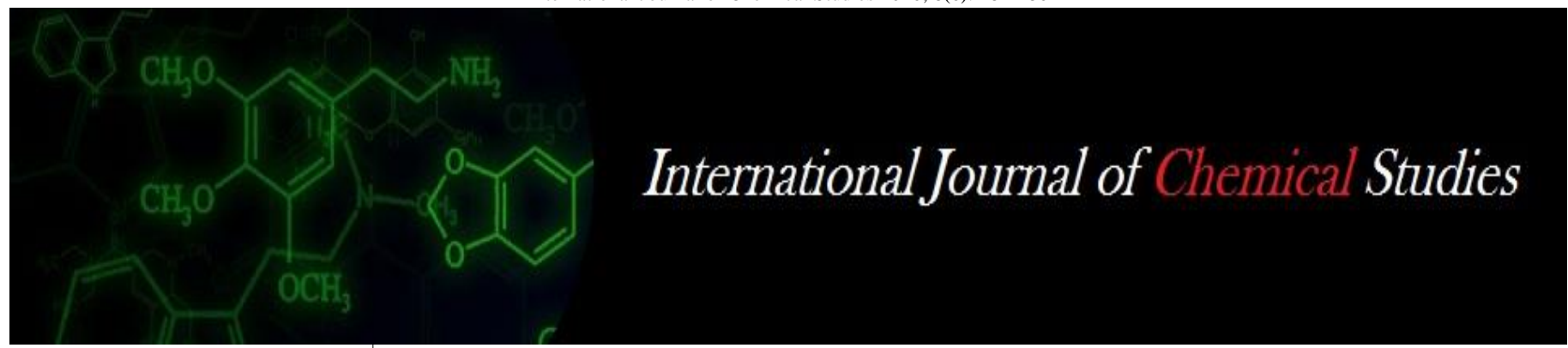

P-ISSN: 2349-8528

E-ISSN: 2321-4902

www.chemijournal.com

IJCS 2020; 8(4): 182-186

(C) 2020 IJCS

Received: 05-05-2020

Accepted: 09-06-2020

Soumya Mishra

Department of Plant Physiology, OUAT, Bhubaneswar, Odisha India

\section{Manoranjan Kar}

Department of Plant Physiology, OUAT, Bhubaneswar, Odisha

India

\section{Physiological performance of rice (Oryza sativa) genotypes under submergence stress in Odisha}

\section{Soumya Mishra and Manoranjan Kar}

DOI: https://doi.org/10.22271/chemi.2020.v8.i4c.9686

\begin{abstract}
Complete submergence of low land rice crops during flash floods occurs in large areas of South-East Asia, when plants may be completely under water for up to 1-2 weeks resulting in an increase mortality of plants vis-à-vis low productivity of rice crops. The present experiment was conducted in Adaptive Research Station, Sakhigopal, Puri during kharif 2017 to screen out the rice genotypes for submergence adaptation traits under agro-climatic ecosystem of Odisha. The present study indicated that among the selected genotypes, Varsadhan, Hanseswari and Champa contributed highest yield.
\end{abstract}

Keywords: Rice, submergence, genotypes, physiological performance

\section{Introduction}

Approximately 30 per cent of the cultivated rice area in India is prone to crop damage from prolonged flooding. Flooding is an environmental stress in many natural and man-made ecosystems world-wide. Anthropogenically-induced global climate change is expected to increase the frequency and severity of flooding events (Arnell and Liu, 2001). Rice is often the only cereal that can be grown in flood prone ecosystem. Uncertainty of rainfall coupled with water logging or submergence stress is a major factor affecting the rice yield in India and as well as in Odisha which is one of the important constraints in India, particularly in the eastern Indian states (Sarkar et al., 2006 and 2009). It is estimated that the flood affected area has more than doubled in size from about 5 per cent ( 19 million hectares) to about 12 per cent (40 million hectares) of India's geographic area(world bank report). The principal cause of damage to plants grown in submergence soil is inadequate supply of oxygen to the submerged tissues as a result of slow diffusion of gases in water and rapid consumption of $\mathrm{O}_{2}$ by soil microorganisms. Unlike other crop plants, Rice has some adaptive traits for tolerance of submergence. One of the traits is formation of the longitudinal interconnection of gas spaces called arenchyma that enables internal aeration between shoots and roots. The second trait is the "escape strategy". This involves the promotion of elongation of leaves and/or stems by entrapped ethylene. This enables plants to resume aerobic metabolism and photosynthetic fixation of $\mathrm{CO}_{2}$ by raising their shoots above water.

Agriculture in Odisha in a way is synonymous to rice cultivation. In Odisha, rice is grown in an area of 44 lakh hectares with an average productivity of $2.3 \mathrm{MT} / \mathrm{ha}$ which is much less in comparison to national average of $104.3 \mathrm{MT} \mathrm{ha}^{-1}$. The vagaries of monsoon play havoc in cropping seasons affecting the yield negatively. Rice being staple crop in Odisha, farmers have natural liking for growing rice. Rice plants that exhibit only limited elongation during submergence often show tolerance to complete flooding. Some researchers have suggested that the ideal response to submergence is submergence tolerance together with some elongating ability (Mohanty, 2000). The major morphological and physiological submergence tolerant traits are slow leaf elongation, less chlorosis, high carbohydrate reserve storage during submergence and prompt re-adaptation to the aerial environment after de-submergence (Setter et al., 1997; Ito et al., 1999; Ram et al., 2002; Jackson and Ram, 2003) [13, 11, 7]. With this backdrop, the current study was conducted in Adaptive Research Station, Sakhigopal, Puri during Kharif 2015 to screen out the rice genotypes for submergence adaptation traits under agro-climatic ecosystem of Odisha.
Corresponding Author: Soumya Mishra Department of Plant Physiology, OUAT, Bhubaneswar, Odisha India 


\section{Materials and Methods}

Seven rice genotypes (180 days duration) namely Varsadhan, Hanseswari, Sarala, Jaladhan-1, Jaladhan-2, Champa and Bankoi were employed in the study. The seeds of these varieties were line sown in separate seed beds in wet season (at the middle of July) for seedling development. The main plot was divided into three replications. The experimental design adopted for this research work was simple randomized block design (RBD).

\section{Pre-Harvest Observations}

a) Shoot dry matter and its partitioning at successive growth stages

Two hills from each plot were randomly uprooted at heading and maturity stages for morpho-physiological observations. Plant parts such as stem, leaf and panicle were separated. The leaf area was measured by multiplying apparent leaf area (length and maximum breadth) with constant leaf area factor i.e., 0.725 at vegetative stage, 0.80 at maturity (Yoshida, 1981). The plant parts were dried separately in a hot air oven at $90^{\circ} \mathrm{C}$ for 48 hours. The dry weight of different plant parts was recorded at each growth stage and expressed in $\mathrm{g} / \mathrm{m}^{2}$. Then it was ground to powder for further laboratory analysis.

b) Growth Analysis parameters

Leaf Area Index (LAI): LAI is expressed as the ratio of the leaf area (A) (only one side) to the ground area (P) occupied by the crop

$\mathrm{LAI}=\mathrm{A} / \mathrm{P}$

Leaf Weight Ratio (LWR): LWR is expressed as the ratio of leaf dry weight $\left(\mathrm{W}_{0}\right)$ to the total plant dry weight $(\mathrm{w})$

$\mathrm{LWR}=\mathrm{W}_{\mathrm{O}} / \mathrm{W}$

Specific Leaf Area (SLA): SLA is the ratio between leaf areas $(\mathrm{A})$ and leaf dry weight $\left(\mathrm{W}_{\mathrm{L}}\right)$

$\mathrm{SLA}=\mathrm{A} / \mathrm{W}_{\mathrm{L}}$

Specific Leaf Weight (SLW): SLW is the ratio between leaf dry weight $\left(\mathrm{W}_{\mathbf{L}}\right)$ and leaf area $(\mathrm{A})$

$\mathrm{SLR}=\mathrm{W}_{\mathrm{L}} / \mathrm{A}$

Leaf Area Duration (LAD): LAD is defined as the leaf area index integrated over time

$$
L A D=\frac{A_{2}-A_{1}}{L_{n} A_{2}-L_{n} A_{1}} \times\left(t_{2}-t_{1}\right)
$$

Where,

$\mathrm{A}_{1}=$ Leaf area index at the start of test period

$\mathrm{A}_{2}=$ Leaf area index at the end of test period

$\mathrm{t}_{2}-\mathrm{t}_{1}=$ Period in days between initial and final observation

Leaf area ratio (LAR): LAR is defined as the ratio between leaf area (A) and total plant dry weight (W)

$\mathrm{LAR}=\mathrm{A} / \mathrm{W}$

\section{Post-Harvest Observation}

At physiological maturity, ten hills from each variety under each replication covering an area of $2000 \mathrm{~cm}^{2}$ were cut just above the ground level leaving border rows on all sides for recording Plant height, Number of tillers/hill, Number of effective tillers/hill, Number of grains/panicle, Number of fertile grains/panicle Sterility percentage at maturity, 1000 seed weight, Grain yield ( $\left.\mathrm{q} \mathrm{ha}^{-1}\right)$,Total bio-mass above ground level $\left(\mathrm{g} / \mathrm{m}^{2}\right)$ and its partitioning into leaf, stem and panicle

\section{Results and Discussion}

Periodical observations of physiological and morphological aspects of plants were made at specific days after flowering (DAF) and significant variations were recorded under normal and submerged conditions.

It was revealed from Table 1 that the number of tillers before submergence (water depth $45.5 \mathrm{~cm}$ ) was maximum (12.17) in Varshadhan. But after submergence for a period of 10 days, Varsadhan exhibited highest number of tillers (9.40) with a decrease of $22.76 \%$ whereas the minimum value of the same was recorded in Bankoi (5.70) with a decrease of $31.5 \%$ before the submergence. Effective tillers per hill was highest in Varsadhan (7.33) and the lowest value was exhibited in Bankoi (3.56). Due to submerged condition the maximum percentage of effective tillers was noted with Varsadhan where as the minimum value of the same (62.36) was recorded in Sarala. Data indicated that before the submergence the highest plant height was exhibited by Varsadhan $(149.53 \mathrm{~cm})$ followed by Hansewari $(139.96 \mathrm{~cm})$ whereas lowest value of the same was showed by Bankoi $(110.50 \mathrm{~cm})$. When the crop was submerged for a period of 10 days Varsadhan showed maximum plant height $(180.37 \mathrm{~cm})$ with an increase of $20.62 \%$. It was observed that shoot elongation of Varshadhan as compared to susceptible genotypes like Bankoi was faster before submergence but during submergence the growth is slower. Singh et al., (2001) reported better survival with lower shoot elongation during submergence. Similarly Bailey-serres and Voesenek (2008) documented that submergence tolerant plants acquire LOQS strategy i.e low oxygen quiescent syndrome strategy which offers plants better chances to survive under deep-short term flooding where shoot emergence seems to represent a higher cost of energy and might compromise eventual recovery when the water recedes. 
Table 1: Plant height, Number of tillers / hill, Number of effective tillers/hill of rice genotypes.

\begin{tabular}{|c|c|c|c|c|c|c|}
\hline \multirow{2}{*}{ Variety } & \multicolumn{2}{|c|}{ Plant Height } & \multicolumn{2}{c|}{ No. of Tillers/hill } & \multirow{2}{*}{ No. of Effective Tillers/hill } & \multirow{2}{*}{ \% of Effective Tillers/hill } \\
\cline { 2 - 5 } & $\mathbf{B S}$ & $\mathbf{A S}$ & BS & AS & 7.33 & 77.97 \\
\hline Varsadhan & 149.53 & $180.37(20.62 \%)$ & 12.17 & $9.40(-22.76 \%)$ & 7.05 & 76.63 \\
\hline Hanseswari & 139.96 & $175.50(27.2 \%)$ & 9.33 & $9.20(-1.39 \%)$ & 3.91 & 62.36 \\
\hline Sarala & 11.43 & $166.80(49.6 \%)$ & 9.77 & $6.27(-35.82 \%)$ & 5.02 & 67.20 \\
\hline Jaladhan-1 & 132.01 & $176.23(33.47 \%)$ & 9.33 & $7.47(-19.93 \%)$ & 4.54 & 66.76 \\
\hline Jaladhan-2 & 127.71 & $173.53(35.87 \%)$ & 9.33 & $6.80(-27.11 \%)$ & 5.85 & 66.45 \\
\hline Champa & 136.18 & $178.70(31.22 \%)$ & 11.53 & $8.40(-27.14 \%)$ & 3.56 & 62.45 \\
\hline Bankoi & 110.50 & $158.03(43.01 \%)$ & 8.33 & $5.70(-31.57 \%)$ & 5.32 & \\
\hline Mean & 129.33 & 172.73 & 9.97 & 7.60 & 0.040 & \\
\hline SEM & 0.751 & 0.460 & 0.862 & 0.077 & 0.124 & \\
\hline C.D 5\% & 2.316 & 1.418 & 2.658 & 0.228 & 1.314 & \\
\hline C.V & 1.007 & 0.461 & 14.988 & 1.689 & & \\
\hline
\end{tabular}

$\mathrm{N}$ : B: - Figure in the parentheses indicates percentage of increase or decrease over previous observation

$\mathrm{BS}=$ Before Submergence

$\mathrm{AS}=$ After Submergence

Leaf area index depicted in Table 2 indicated that before submergence, Champa showed highest LAI (12.33) while Sarala gave the lowest value (9.53). Observation taken after the submergence indicated that there was drastic reduction in LAI irrespective of genotypes. However, Varsadhan showed highest value (4.80) and lowest value (3.50) was observed in Sarala. Significant difference was found among the genotypes. Rice plant is composed of leaves that are physiologically different in age and activity. For emergence of a leaf, rice plant takes initially 4 to 5 days but afterwards it takes 7-8 days before the initiation of panicle (Yoshida, 1981). Hence, during vegetative stage rice crop attains maximum LAI even upto to 13 or more. However, the critical LAI value at maximum crop photosynthesis is about 6-7 under normal weather conditions. Due to submergence specific leaf weight (SLW) and leaf area ratio (LAR) decreased. There was highly positive correlation between LAI with grain yield, grains per panicle, shoot Dry matter and harvest and poor correlation with test weight (Table 7).

Table 2: Leaf area index (LAI), Specific leaf area (SLA) and Specific leaf weight (SLW) in response to submerged condition of rice genotypes

\begin{tabular}{|c|c|c|c|c|}
\hline \multirow{2}{*}{ Variety } & \multicolumn{2}{|r|}{ LAI } & \multirow{2}{*}{$\begin{array}{c}\text { SLA } \\
\left(\mathrm{cm}^{2} / \mathrm{g}\right)\end{array}$} & \multirow{2}{*}{$\begin{array}{c}\text { SLW } \\
\left(\mathrm{mg}^{\left.-\mathrm{cm}^{2}\right)}\right.\end{array}$} \\
\hline & BS & AS & & \\
\hline Varsadhan & 11.77 & $4.80(-59.21 \%)$ & 142.97 & 3.37 \\
\hline Hanseswari & 11.93 & $4.7(-60 \%)$ & 151.62 & 3.57 \\
\hline Sarala & 9.53 & $3.50(-63.2 \%)$ & 193.00 & 4.42 \\
\hline Jaladhan-1 & 10.40 & $3.93(-62.2 \%)$ & 164.91 & 4.28 \\
\hline Jaladhan-2 & 10.53 & $3.80(-63.9 \%)$ & 162.87 & 4.39 \\
\hline Champa & 12.33 & $4.03(-67.3 \%)$ & 164.57 & 4.24 \\
\hline Bankoi & 11.00 & $3.73(-66 \%)$ & 210.13 & 4.02 \\
\hline Mean & 11.07 & 4.08 & 170.01 & 4.04 \\
\hline SEM & 0.179 & 0.137 & 0.834 & 0.119 \\
\hline C.D 5\% & 0.552 & 0.423 & 2.571 & 0.368 \\
\hline C.V & 2.803 & 5.833 & 0.850 & 5.120 \\
\hline
\end{tabular}

Among the rice genotypes, leaf area ratio (LAR) was recorded maximum $\left(57.67 \mathrm{~cm}^{2} / \mathrm{g}\right)$ at flowering stage in Varsadhan due to submerged condition but Bankoi exhibited lowest value $\left(46.95 \mathrm{~cm}^{2} / \mathrm{g}\right.$ ) (Table 3). Significant difference was found among the genotypes. There was highly positive correlation between LAR with grain yield, grains per panicle, shoot Dry matter (Table 7). The highest RGR value (37.95 mg/g/day) was recorded in Varsadhan and Bankoi $(32.40 \mathrm{mg} / \mathrm{g} /$ day) showed the lowest value $(33.50 \mathrm{mg} / \mathrm{g} / \mathrm{day})$ due to submerged condition. A highly positive correlation is found between RGR with grain yield, grains per panicle, shoot DM and negative correlation with sterility percentage (Table 7). Comparison of LWR among the genotypes revealed that Varsadhan had the highest LWR $(0.29 \mathrm{~g} / \mathrm{g})$. On the contrary, the lowest LWR was showed by Bankoi $(0.20 \mathrm{~g} / \mathrm{g})$. Like RGR there was highly positive correlation between LWR with other yield parameters.

Table 3: Leaf area ratio (LAR), relative growth rate (RGR) and leaf weight ratio (LWR) in rice genotypes

\begin{tabular}{|c|c|c|c|}
\hline Variety & LAR $\mathrm{cm}^{2} / \mathrm{g}$ & RGR mg/g/day & LWR g/g \\
\hline Varsadhan & 57.67 & 37.95 & 0.29 \\
\hline Hanseswari & 57.35 & 37.03 & 0.28 \\
\hline Sarala & 46.12 & 34.27 & 0.21 \\
\hline Jaladhan-1 & 52.14 & 36.46 & 0.23 \\
\hline Jaladhan-2 & 48.69 & 36.29 & 0.24 \\
\hline Champa & 56.54 & 36.50 & 0.24 \\
\hline Bankoi & 46.95 & 33.50 & 0.20 \\
\hline Mean & 52.21 & 36.00 & 0.24 \\
\hline SEM & 0.147 & 0.319 & 0.007 \\
\hline C.D 5\% & 0.453 & 0.983 & 0.022 \\
\hline C.V & 0.488 & 1.535 & 5.176 \\
\hline
\end{tabular}

The data presented in Table 4 indicated that among the genotypes the highest crop growth rate (CGR) was obtained from Varsadhan $\left(11.45 \mathrm{mg} / \mathrm{m}^{2} /\right.$ day) while the lowest value of the same was recorded from Bankoi $\left(8.46 \mathrm{mg} / \mathrm{m}^{2} /\right.$ day) under submerged condition at flowering stage. The C.V. value indicates there was variation among the genotypes in respect of CGR. There was highly positive correlation between CGR with grain yield, grains per panicle, shoots DM, survival percentage and poor correlation with 1000 grain weight \& negative correlation with sterility percentage (Table 7). Varsadhan exhibited maximum NAR value $\left(39.58 \mathrm{mg} \mathrm{dm}^{2-1}\right.$ day $^{-1}$ ) (Table 4). On the contrary, lowest value of the same was observed by Sarala (34.60 $\mathrm{mg} \mathrm{dm}^{-2}$ day $^{-1}$ ). The C.V. value indicates there is small variation in NAR activities among the genotypes. It has been documented that leaf area duration (LAD) manifests the magnitude and persistence of leaf area or leafiness during growth of the crop. It reflects seasonal integral of light interception which is highly correlated with yield (Gardner et al., 1988). It is because biomass duration (BMD) is analogous to LAD of which LAI or leaf area is determinant. It has been discussed elsewhere that submergence tremendously affects leaf area and its ancillary characters. Irrespective of genotypes after submergence LAD and LWR were reduced as compared to non-stressed condition. So the tolerant genotypes have higher LAD and LWR than susceptible genotypes. In respect to these 
two parameters the sequence followed in an order of: Varsadhan > Hanseswari > Champa > Jaladhan-1 > Jaladhan-2 $>$ Bankoi > Sarala.

Table 4: Crop Growth Rate (CGR), Net Assimilation Rate (NAR), leaf area duration (LAD) in rice genotypes

\begin{tabular}{|c|c|c|c|}
\hline Variety & $\begin{array}{c}\text { CGR } \\
\mathbf{m g} / \mathbf{m}^{2} / \mathbf{d a y}\end{array}$ & $\begin{array}{c}\mathbf{N A R} \\
\mathbf{m g} / \mathbf{d m}^{2} / \mathbf{d a y}\end{array}$ & $\begin{array}{c}\text { LAD } \\
\text { (in days) }\end{array}$ \\
\hline Varsadhan & 11.45 & 39.58 & 129.82 \\
\hline Hanseswari & 11.01 & 38.95 & 128.25 \\
\hline Sarala & 08.12 & 34.67 & 118.77 \\
\hline Jaladhan-1 & 10.11 & 36.26 & 123.52 \\
\hline Jaladhan-2 & 9.30 & 36.47 & 123.08 \\
\hline Champa & 10.36 & 37.39 & 126.37 \\
\hline Bankoi & 8.46 & 36.70 & 120.13 \\
\hline Mean & 9.83 & 35.03 & 124.28 \\
\hline SEM & 0.146 & 0.134 & 0.124 \\
\hline C.D 5\% & 0.450 & 0.415 & 0.384 \\
\hline C.V & 2.578 & 0.632 & 0.174 \\
\hline
\end{tabular}

Under submerged condition maximum number of grains per panicle was contributed by Varsadhan (242.61/panicle) whereas the minimum value of the same was showed by Bankoi (206.51/panicle). As per the C.V value there was greater variation among the genotypes. Varsadhan significantly showed maximum number of fertile grains (205.50/panicle) as compared to other genotypes under submergence. However, Bankoi under waterlogged condition exhibited lowest number of fertile grains (156.57/panicle). Sterility percentage was maximum in Sarala $(24.73 \%)$ due to submergence at flowering stage. On the other hand, sterility percentage was to the tune of $(15.50 \%)$ in Varsadhan. The attributing factors for augmentation in productivity of Varsadhan were due to more number of effective tillers per hill which indicates high survival percentage under submergence and more fertile grains per panicle. Present study revealed that Varsadhan exhibited more numbers (7.33/hill) of effective tillers per hill followed by Hanseswari $(9.20 /$ hill $)$ whereas the minimum value of the same was showed by Bankoi (5.70/hill) which indicates the more survival percentage of the cultivar during submergence. Chen and Wang (2008) informed that there is a greater ability of sink tissues to store sugar. So the number of panicles per hill, effective tillers per hill and 1000 grain weight are regarded as the selection criteria for adequate production of grain yield under submergence. These earlier findings coincide with the present findings.

Table 5: Panicle length, grains/panicle, No. of fertile grains/panicle \& sterility\% in rice genotypes

\begin{tabular}{|c|c|c|c|c|}
\hline Variety & Panicle length (cm) & No. of Grains/ Panicle & No. of fertile grains/ panicle & Sterility (\%) \\
\hline Varshadhan & 27.63 & 242.61 & 205.00 & 15.50 \\
\hline Hanseswari & 26.63 & 232.73 & 194.33 & 16.50 \\
\hline Sarala & 25.77 & 217.02 & 163.33 & 24.73 \\
\hline Jaladhan-1 & 25.73 & 215.83 & 171.67 & 20.77 \\
\hline Jaladhan-2 & 24.77 & 216.69 & 170.67 & 21.23 \\
\hline Champa & 26.17 & 226.38 & 153.00 & 19.17 \\
\hline Bankoi & 26.80 & 206.51 & 177.81 & 24.13 \\
\hline Mean & 26.21 & 222.54 & 2.371 & 20.29 \\
\hline SEM & 0.387 & 3.389 & 7.305 & 0.221 \\
\hline C.D 5\% & 1.195 & 10.444 & 2.309 & 0.683 \\
\hline C.V & 2.563 & 2.638 & & 1.892 \\
\hline
\end{tabular}

The grain yield of different genotypes tested under submerged condition was presented in Table 6. Highest yield was obtained from Varsadhan (26.70 q/ha) whereas lowest grain yield was obtained from Sarala $(19.03 \mathrm{q} / \mathrm{ha})$ and the percentage of reduction in yield was nearly $28.7 \%$ in Sarala as compared to Varsadhan. Significant difference in respect to yield was found among the genotypes. Data presented in
Table 6 indicated that under submerged condition highest test weight was exhibited by Varsadhan (24.58 g) whereas the lowest value was showed by Sarala (19.46 g). Under submerged condition significant difference exhibited in both replication and genotypes. Poor correlation exhibited between test weight and grain yield.

Table 6: 1000 grain weight, grain yield in rice genotypes

\begin{tabular}{|c|c|c|}
\hline Variety & 1000 grain weight (g) & ${\text { grain yield }\left(\mathbf{q} \mathbf{~ h a}^{\mathbf{1}}\right)}^{26.70}$ \\
\hline Varshadhan & 24.58 & 26.03 \\
\hline Hanseswari & 21.14 & 19.03 \\
\hline Sarala & 19.46 & 22.57 \\
\hline Jaladhan-1 & 20.24 & 21.80 \\
\hline Jaladhan-2 & 20.54 & 23.57 \\
\hline Champa & 21.15 & 19.83 \\
\hline Bankoi & 23.22 & 22.79 \\
\hline Mean & 21.47 & 0.157 \\
\hline SEM & 0.105 & 0.484 \\
\hline C.D 5\% & 0.325 & 1.194 \\
\hline C.V & 0.853 & \\
\hline
\end{tabular}

Data presented in Table 7 revealed that grain yield had significantly positive correlation with number of grains per panicle and fertile grains per panicle and had negative correlation with percentage of sterility. The above findings regarding the relationship of grain yield with its attributes are in accordance with the findings of many workers whose report indicated that the rice yield is positively associated with number of grains per panicle, number of fertile grains per panicle and number of effective tillers per hill (Islam et al., 2010, Fageria et al., 2011, Li et al., 2012) ${ }^{[6,5,9]}$. So it was 
contemplated from present investigation that importance should be given on number of effective tillers/hill, number of fertile grains per panicle and dry matter accumulation after the submergence to obtain sustainable productivity of rice crops under water stress (submergence) environment.

Table 7: Correlation coefficient relation matrix between crop yield and yield attributing characters with physiological parameters of rice genotypes

\begin{tabular}{|c|c|c|c|c|c|c|c|}
\hline & $\begin{array}{c}\text { Grain } \\
\text { yield/ha }\end{array}$ & Grains/panicle & $\begin{array}{c}\text { 1000 grain } \\
\text { weight }\end{array}$ & $\begin{array}{c}\text { Shoot DM/m } \\
\text { harvest }\end{array}$ & $\begin{array}{c}\text { Panicle } \\
\text { length }\end{array}$ & $\begin{array}{c}\text { Survival } \\
\text { percentage }\end{array}$ & Sterility percentage \\
\hline Grain yield/ha & & 0.898 & 0.461 & 0.980 & 0.522 & 0.429 & -0.998 \\
\hline LAI & 0.964 & 0.880 & 0.551 & 0.984 & 0.656 & 0.483 & -0.955 \\
\hline SLA & -0.8976 & -0.842 & -0.155 & -0.808 & 0.151 & -0.253 & 0.912 \\
\hline SLW & -0.789 & -0.747 & -0.759 & -0.877 & 0.851 & -0.639 & 0.770 \\
\hline LWR & 0.962 & 0.937 & 0.402 & 0.943 & 0.447 & 0.374 & -0.969 \\
\hline LAR & 0.952 & 0.864 & 0.373 & 0.932 & 0.520 & 0.257 & -0.951 \\
\hline RGR & 0.915 & 0.845 & 0.227 & 0.833 & 0.212 & 0.320 & -0.928 \\
\hline NAR & 0.991 & 0.927 & 0.494 & 0.984 & 0.533 & 0.417 & -0.994 \\
\hline CGR & 0.986 & 0.864 & 0.418 & 0.950 & 0.484 & 0.424 & -0.983 \\
\hline LAD & 0.991 & 0.899 & 0.478 & 0.974 & 0.512 & 0.405 & -0.994 \\
\hline
\end{tabular}

\section{References}

1. Adak MK, Das Gupta DK. Metabolic activities in some rice varieties under submergence stress. Indian Journal of plant physiol. 2002; 6:312-316.

2. Bailey-serres J, Voesenek LACJ. Flooding stress: acclimations and genetic diversity. Annual review of plant- Biology. 2008; 59:313-339.

3. Chen HJ, Wang SJ. Molecular regulation of sink source transition in rice leaf sheath during heading period. Acta Physiol Plant. 2008; 30:639-649.

4. Dawe D. The changing structure of the world rice market, 1950-2000. Food Policy. 2002; 27(4):355-370.

5. Fageria NK, Moreia A. Grain yield was significantly related with Plant height, Biomass, Panicle number, HI; journal of plant nutrient. 2011; (34):361-370.

6. Islam MS, Peng S. Comparative study on yield and yield attributes of hybrids, and NPT rice genotypes in a tropical irrigated ecosystem, Bangladesh J. Agril. Res. 2010; 35(2):343-353

7. Jackson MB, Ram PC. Physiological and molecular basis of susceptibility of rice plants to complete submergence. Ann. Bot. 2003; 91:227-241

8. Kawano N, Ito O, Sakagami JI. Morphological and physiological responses of rice seedlings to complete submergence (flash flood). Ann Bot. 2009; 103:161-169.

9. Li xiaobai, Agrama Hesham. Unrevealing the complex trait of harvest index with association on mapping rice (Oryza sativa).PLOS ONE. 2012; 7(1).

10. Mohanty HK, Mallik S, Grover. Prospects of improving flooding tolerance in lowland rice varieties by conventional breeding and genetic engineering. Curr. Sci. 2000; 78:132-137.

11. Ram PC. Submergence tolerance in rainfed lowland rice: physiological basis and prospects for cultivar improvement through market-aided breeding; Field Crop Res. 2002; 76:131-152.

12. Sarkar RK, Reddy. Physiological traits on submergence tolerance rice and implication for crop improvement, Current science. 2006; 91(7):892-905.

13. Setter. scientists Physiology and genetics of submergence tolerance in rice. Ann. Bot. 1997; 79(Suppl.A):67-77.

14. Yoshida S. Fundamental of Crop Science. Intl. Rice Res. Inst., Los Banos, Leguna, Philipines, 1981, 269. 